\title{
Homozygous and Frequent Deletion of Proximal 8p Sequences in Human Prostate Cancers: Identification of a Potential Tumor Suppressor Gene Site
}

\author{
Madhu A. Prasad, ${ }^{1,2}$ Tanya M. Trybus, ${ }^{1,2}$ Kirk J. Wojno, ${ }^{1-3}$ and Jill A. Macoska ${ }^{1,2 *}$ \\ 1Department of Surgery, U niversity of Michigan, Ann Arbor, Michigan \\ ${ }^{2}$ C omprehensive $C$ ancer $C$ enter, U niversity of Michigan, A nn A rbor, Michigan \\ ${ }^{3}$ Department of Pathology, U niversity of Michigan, A nn A rbor, Michigan
}

By using tissue microdissection and polymerase chain reaction (PCR) techniques, we examined 85 prostate tumors that were paired with no rmal tissues from the same patients for allelic loss at 26 highly polymorphic microsatellite sequences, 21 spanning $8 p$ and 5 localized to 8q. Sixty-four tumors (75\%) demonstrated loss of at least one 8p locus. Separate distal and proximal regions of deletion were observed as well as an intervening, staggered breakpoint. A novel region of homozygous deletion of sequences at the D8S87 locus was detected both by multiplex PCR and by fluorescence in situ hybridization within this breakpoint region. These data suggest that a tumor-suppressor gene mapping to proximal $8 p$ is deleted frequently and is likely to be important for tumorigenesis in prostate tumors. Genes Chromosomes Cancer 23:255-262,1998.

(c) 1998 W iley-Liss, Inc.

\section{INTRODUCTION}

It is likely that many genetic and epigenetic events are involved in tumorigenesis. In particular, recent cytogenetic and molecular studies have suggested that deletion or rearrangement of sequences that map to the short arm of chromosome 8 may be permissive for tumorigenesis in several organ systems. In prostate carcinoma, early work by Bergerheim et al. (1993) utilizing Southern blot techniques observed high frequencies of deletion of distal $8 p$ sequences in human prostate tumors, suggesting that a breakpoint existed between the NEFL locus at 8p21 and the PLAT locus at 8p218p11. Subsequent work by Bova et al. (1993) and our laboratory (Wolman et al., 1992; Macoska et al., 1993) identified a major region of deletion mapping to 8 p22 in human prostate cancer (PCa), which is characterized by a homozygous deletion mapping within the $8 \mathrm{p} 22-\mathrm{p} 23$ region in a prostate tumor (Bova et al., 1996). The use of polymerase chain reaction (PCR) and fluorescence in situ hybridization (FISH) techniques in our laboratory and by others confirmed frequent heterozygous loss of distal 8p sequences (Macoska et al., 1994; MacGrogan et al., 1994; Sakr et al., 1994) and showed that this region of deletion could be quite extensive, including the entire $8 \mathrm{p}$ chromosome arm or large portions of $8 \mathrm{p}$ extending from $8 p$ ter to $8 \mathrm{p} 11-12$ (MacGrogan et al., 1994; Trapman et al., 1994). We later reported interstitial deletions of distal sequences mapping to $8 \mathrm{p} 22$ or $8 \mathrm{p} 21$ or proximal loci mapping to $8 \mathrm{p} 11-12$ in human prostate tumors
(Macoska et al., 1995). Other laboratories reported deletional domains encompassing or including $8 \mathrm{p} 22$ and 8p21-p12 (Vocke et al., 1996), interstitial losses and homozygous deletions at 8p21 and 8p22 (Kagan et al., 1995; Suzuki et al., 1995), interstitial losses of two separate proximal deletional domains (Crundwell et al., 1996), and isolation of a potential tumor suppressor gene mapping to $8 \mathrm{p} 21.3-\mathrm{p} 22$ (Fujiwara et al., 1995). Recent studies have also mapped a putative prostate metastasis suppressor gene to the 8p21-p12 region (Nihei et al., 1996).

Taken together, these studies suggest that there are at least two large $8 p$ sequence domains that are deleted in prostate, bladder, and other cancers: distal sequences encompassing 8pter-p21 (sometimes divided further into smaller, separate deletional domains) and proximal sequences encompassing $8 \mathrm{p} 11-\mathrm{p} 12$. In this report, we present data that demonstrate frequent and sometimes homozygous deletion of specific sequences mapping to proximal $8 \mathrm{p}$. This information should facilitate the isolation and cloning of one or more putative proximal $8 \mathrm{p}$ tumor-suppressor genes that are inactivated in a variety of human cancers.

\footnotetext{
Supported by: National Institutes of Health; Contract Grant number: R29 CA60948.

*Correspondence to: Jill A. Macoska, Ph.D., Department of Surgery, Section of Urology, The University of Michigan School of Medicine, 7306 CGGC, 1500 East Medical Center Drive, Ann Arbor, MI 48109-0946. E-mail: jcoska@umich.edu

Received 10 February 1998; Accepted 1 June 1998
} 


\section{MATERIALS AND METHODS}

\section{Tissue Characterization}

Prostate tissue was obtained after radical prostatectomy from 85 patients diagnosed with PCa. After an initial pathologic evaluation of radical prostatectomy tissue, presumed malignant and normal tissue was snap frozen in liquid nitrogen and stored at $-70^{\circ} \mathrm{C}$. Tumor specimens comprising areas of at least $70 \%$ malignant cells and nontumor specimens comprising normal or hyperplastic epithelium were serially sectioned at 4 microns. One section was stained with hematoxylin/eosin for histologic evaluation, and discrete areas of benign or malignant glands were then excised from adjacent nonstained sections. DNA was extracted as described previously (Macoska et al., 1993, 1994, 1995; Sakr et al., 1994). Serum prostate-specific antigen (PSA) values were obtained within a 1 -week period prior to surgery.

\section{Analysis of DNA for Allelic Loss}

PCR was utilized for amplification of 26 sequences containing highly polymorphic microsatellite repeat markers at loci of interest on chromosome $8: 21$ loci that map to $8 \mathrm{p}$ and 5 that map to proximal 8q. The linkage order of these markers has been reported as pter-D8S549-D8S1715D8S1116/D8S1739-D8S1725-NEFL-D8S137-D8S1423-D8S540/D8S1125/D8S259/D8S513/D8S1105/D8S505-D8S535-D8S87-D8S255-D8S1118D8S1121-AFMa295zd5-D8S1104-D8S531-D8S519-D8S1098-D8S538-D8S589-qter (where / indicates markers of uncertain relative order; see Fig. 1). Microsatellite-specific primer sequences mapping near the WRN locus at the D8S1105 locus were as reported (Ye et al., 1995). Cytogenetic localizations were available for the following markers: 8pterp23.1, D8S549; 8p21, NEFL; 8p12, D8S87; and 8q11.2-q12, D8S1104 (as reported by the Human Genome Data Base; GDB; http://gdbwww.gdb.org). Primer sequences, additional linkage and contig information, and genetic mapping information were obtained from public databases maintained by the GDB, the Center for Genome Research at the Whitehead Institute for Biomedical Research (http:// www-genome.wi.mit.edu/), the Cooperative $\mathrm{Hu}-$ man Linkage Center (CHLC; http://www.chlc.org/), and the National Center for Biotechnology Information (http://www.ncbi.nlm.nih.gov/), as accessed through the Internet.

PCR reactions were performed as described previously (Trybus et al., 1996). Aliquots of each reaction were electrophoresed on $6 \%$ acrylamide/7 $\mathrm{M}$ urea sequencing gels, and the gels were autoradiographed. Allelic loss was scored when the ratio of allelic signal intensities in tumor tissue was $\leq$ $50 \%$ of that for the same alleles in normal tissue from the same heterozygous patient by two independent observers (M.A.P. or T.M.T. and J.A.M.). Statistical analysis was performed by $\chi^{2}$ test, with $P$ values $<0.05$ considered statistically significant.

Instances of putative homozygous loss were investigated further by multiplex PCR analysis, in which two primer sets were introduced simultaneously into the same reaction mixtures. The failure to produce an amplification product from one of the two amplicons in a multiplex reaction was interpreted as homozygous loss of the sequence that failed to amplify.

\section{Fluorescence In Situ Hybridization}

Slides were prepared from frozen tissues as described previously (Macoska et al., 1994). A clone, 303f13, mapping to the D8S87 locus was isolated by PCR amplification of a microsatellite marker specific for that region from a human BAC DNA library (Research Genetics, Inc., Huntsville, AL). Subsequent analysis confirmed that BAC $303 \mathrm{f} 13$ contains sequences specific for D8S87 (cytogenetically localized to 8p12) and WI-4330 (mapped to chromosome 8 ) and produces no more than two discrete fluorescent signals when it is labeled and hybridized to cut sections of normal prostatic epithelium (see Table 1). These findings are consistent with an exclusive chromosome 8 localization for this BAC. One microgram of BAC $303 \mathrm{f} 13$ was labeled via nick translation with $20 \mu \mathrm{M}$ fluorescein11-dUTP (FluoroGreen; Amersham, Buckinghamshire, United Kingdom). Unincorporated nucleotide was eliminated by passage through Sephadex G-25. The labeled DNA was digested with EcoRI and ethanol precipitated in the presence of Cot-1 $(10 \mu \mathrm{g})$ DNA, yeast tRNA $(25 \mu \mathrm{g})$, and sonicated salmon testes DNA $(25 \mu \mathrm{g})$. The probe was then resuspended in $10 \mu \mathrm{l}$ formamide and combined with an equal volume of hybridization solution (to final concentrations of $25 \%$ dextran sulfate, 2.5 $\mu \mathrm{g} / \mathrm{ml}$ bovine serum albumin, $2.5 \times$ standard saline citrate; SSC). One microliter of rhodamine-labeled chromosome 8 pericentromeric probe DNA (CEP8 SpectrumOrange; Vysis, Downers Grove, IL) was added to the hybridization mixture and applied to the prepared slide, which was coverslipped and sealed. The slide was incubated at $90^{\circ} \mathrm{C}$ for 10 minutes and was then incubated at $37^{\circ} \mathrm{C}$ overnight. Unbound probe was removed by washing the slide 


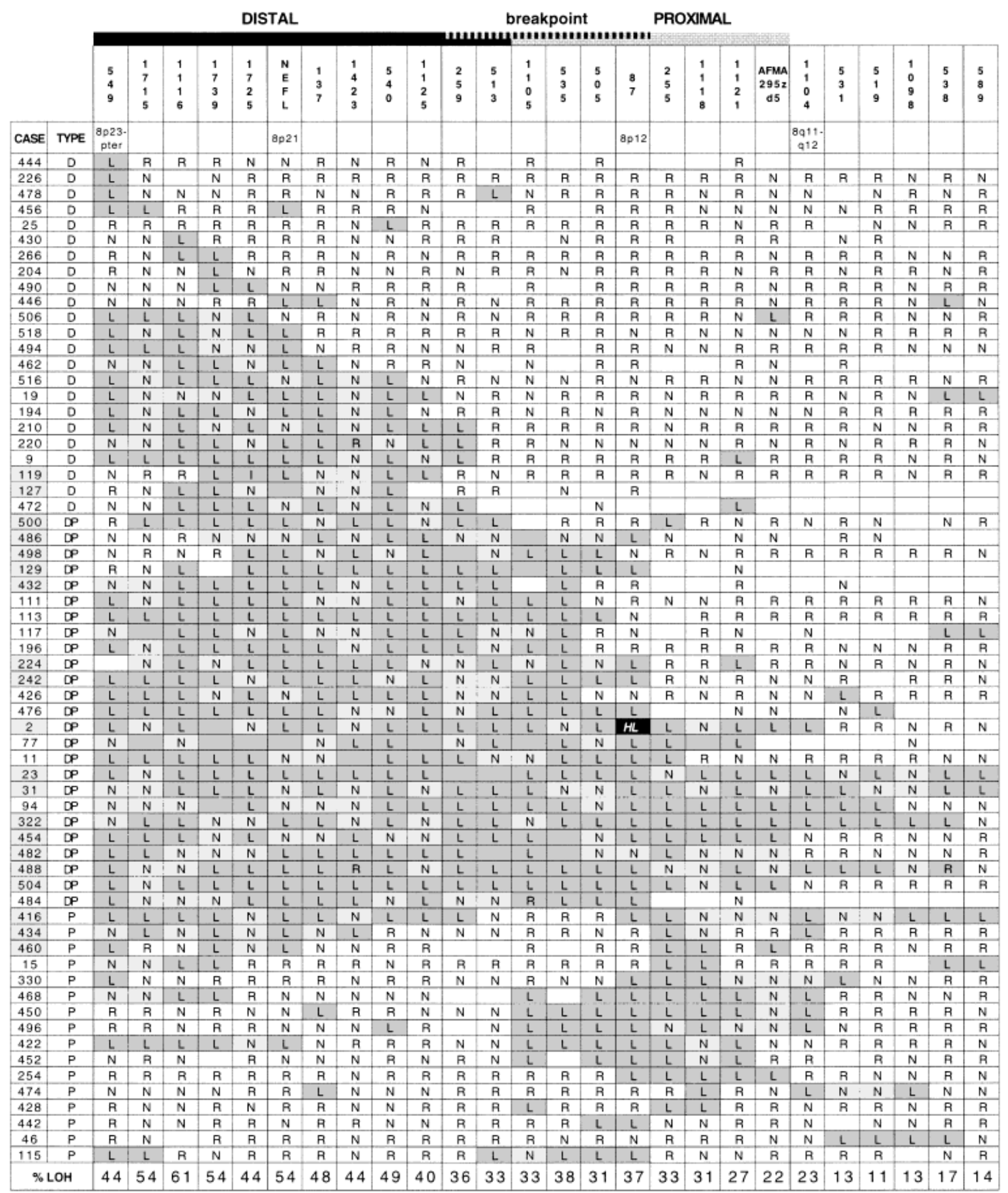

Figure 1. Deletion profile of 64 prostate tumors with allelic loss of $8 p$ sequences. Loci are shown at the top of the figure and are oriented from 8pter on the left to 8cen on the right and refer to "D 8" designations (with the exceptions of the NEFL and AFM295zd5 loci). Prostate tumors are refered to by case number on the $y$-axis. Type refers to major region of deletion, D (distal), P (proximal), or D P (distal + proximal). Allelic loss patterns are indicated as follows: $R$, both alleles retained (white boxes); $N$, not informative (light gray boxes); and L, loss of one allele (dark gray boxes). Extended light and dark gray shaded areas show probable contiguous regions of deletion. The black box designated " $H L$ " shows a region of homozygous allelic loss. The extents of the distal (black bar) and proximal (gray bar) regions of deletion are indicated at the top, as is the breakpoint (black and gray hatched bar). Allelic loss frequencies for individual loci (out of a total of 85 tumors) are shown at the bottom. Specific cases discussed in the text are highlighted. 
TABLE 1. Fluo rescence In Situ Hybridization A nalysis of Homozygo us Deletion at D 8S87

\begin{tabular}{lcc}
\hline $\begin{array}{l}8 p, 8 c \text { Signal } \\
\text { counts }\end{array}$ & $\begin{array}{c}\text { N ormal tissue } \\
\text { nuclei }(\%)\end{array}$ & $\begin{array}{c}\text { Tumor tissue } \\
\text { nuclei }(\%)\end{array}$ \\
\hline $\begin{array}{c}\text { Case } 2 \\
1,1\end{array}$ & $9(5)$ & $8(4)$ \\
1,2 & $26(13)$ & $61(30)$ \\
2,2 & $123(62)$ & $19(10)$ \\
0,2 & $15(7)$ & $97(49)$ \\
O ther & $27(13)$ & $15(7)$ \\
Total & $(100)$ & $(100)$ \\
Total 8p loss & $50(25)$ & $166(83)$ \\
Case 512 & & \\
1,1 & $10(5)$ & $2(1)$ \\
1,2 & $48(24)$ & $46(23)$ \\
2,2 & $108(54)$ & $108(54)$ \\
0,2 & $18(9)$ & $27(13)$ \\
O ther & $16(8)$ & $17(9)$ \\
Total & $(100)$ & $(100)$ \\
Total 8p loss & $76(38)$ & $75(38)$ \\
\hline
\end{tabular}

in $2 \times \mathrm{SSC}$ for 30 minutes each successively at room temperature, at $37^{\circ} \mathrm{C}$, and at $45^{\circ} \mathrm{C}$, then at $70^{\circ} \mathrm{C}$ for 5 minutes. The slide was stored at $4^{\circ} \mathrm{C}$ in $1 \times$ phosphate-buffered detergent $\left(0.1 \mathrm{M} \mathrm{Na}_{2} \mathrm{HPO}_{4}\right.$, $0.1 \mathrm{M} \mathrm{NaH}_{2} \mathrm{PO}_{4}, 0.5 \% \mathrm{NP}-40$ ) (PBD) prior to counterstaining and visualization.

Nuclei were counterstained with DAPI/antifade, and slides were visualized using a mercury light source and appropriate filters (Chroma Optical, Brattelboro, VT) on a photomicroscope (Zeiss Axiophot, Thornwood, NY). The $\mathrm{x}, \mathrm{y}$ coordinates of microscope fields at $\times 1,000$ within areas of appropriate histology of normal and tumor tissues were noted, and nuclei of 200 epithelial cells were enumerated for the BAC and CEP8 probes. Careful attention was given to counting only tissue areas of appropriate histology with good nuclear morphology. Two observers (M.A.P., J.A.M.) independently counted each slide using the same $\mathrm{x}, \mathrm{y}$ coordinates, and the average of the two sets of counts was determined. The values obtained from two observers typically agreed with each other within $10 \%$.

\section{RESULTS AND DISCUSSION}

\section{Frequent and Often Independent Deletion of Distal and Proximal $8 p$ Sequences}

In an effort to define the $8 \mathrm{p}$ regions of deletion, we utilized PCR techniques to determine the allelic loss pattern of 26 highly polymorphic microsatellite sequences spanning $8 \mathrm{p} 23-\mathrm{q} 12$ for 85 paired normal and malignant tissues from cancerous human prostates. This analysis revealed loss of heterozygosity (LOH) of at least one $8 p$ locus in $75 \%$ (64 of 85 ) of the tumors examined. This frequency is consistent with that obtained by other studies using more exacting or semiquantitative techniques, such as tissue laser microdissection (Vocke et al., 1996), phosphorimaging (MacGrogan et al., 1994), or fluorescence in situ hybridization (FISH; Macoska et al., 1994).

The deletion profiles of the 64 tumors with $\mathrm{LOH}$ are shown in Figure 1. Insufficient tissue precluded the complete analysis of six tumors $(472,129,432$, $476,77,484)$. Of the remaining 58 of 85 tumors, four $(2,454,482,504)$ demonstrated LOH for all $8 \mathrm{p}$ loci examined and were likely deleted for the entire $8 \mathrm{p}$ arm. An equivalent number of tumors (cases 23, 31,322 , and 488 ) were deleted for all $8 \mathrm{p}$ and $8 \mathrm{q}$ loci examined and were apparently reduced to monosomy for chromosome 8 . Thus, eight tumors demonstrated substantial losses of chromosome 8 sequences. However, the majority of tumors examined in this study were deleted for extended regions rather than for all $8 \mathrm{p}$ sequences. Among the 64 cases with allelic loss, distal 8p sequences (8pterp21), including D8S549, D8S1715, D8S1116, D8S1739, NEFL, D8S137, D8S1423, D8S540, D8S1125, D8S259, and D8S513 (indicated as "D" in Fig. 1), were deleted in $23(27 \%)$ of tumors examined. Proximal $8 \mathrm{p}$ sequences (8p11-p12), including D8S1105, D8S535, D8S505, D8S87, D8S255, D8SD1118, D8S1121, and AFMA295zd5 (indicated as "P" in Fig. 1), were deleted in 16 cases (25\%). Both distal and proximal sequences ("DP" in Fig. 1) were deleted contiguously in 25 cases (39\%). Thus, separate or independent deletion of distal or proximal sequences (39 cases) was observed more frequently than contiguous deletion of both regions ( 25 cases) in these tumors. It should be noted that, in six cases $(119,127,500,486,498$, 129 ), the most distal portion of an otherwise contiguously deleted distal region was retained.

\section{Identification of a Proximal 8p Breakpoint}

A potential "breakpoint" may be identified from the data shown above in Figure 1. The boundary of this breakpoint appears somewhat "staggered" for many tumors (compare the proximal boundary for cases 498, 432, 224, and 242 with the distal boundary for cases 416,434 , and 460), roughly between D8S137 and D8S87. The maximal extent of this breakpoint can be defined as inclusive of loci D8S259, D8S513, D8S1105, D8S535, D8S505, and D8S87, which are all tightly linked and map within an approximately one megabase region between 64 $\mathrm{cM}$ and $65 \mathrm{cM}$ on the genetic map (as reported by the Center for Genome Research at the Whitehead Institute for Biomedical Research). Although the 
linkage order of these markers is uncertain, they are presented here in the order most consistent with the Whitehead Institute and with our deletion data.

To evaluate data from the current study in terms of what has been reported previously, it is critical to examine the definition of distal and proximal regions of $8 \mathrm{p}$ deletion in these studies. For example, several studies examined $8 p$ loss using the marker D8S259, which comprises a part of the distal border of the $8 p$ breakpoint defined in the present study. Observation of allelic loss patterns near and including D8S259 reported by MacGrogan et al. (1994) shows that 8 of 14 "group II" prostate tumors were deleted for $8 \mathrm{p}$ sequences immediately distal to or inclusive of D8S259, although the marker order D8S259-D8S137-D8S87 was used rather than the D8S137-D8S259-D8S87 order used here. Also, a few tumors were deleted separately for a region proximal to D8S137 in that study (MacGrogan, et al., 1994). Similarly, the study by Takle and Knowles (1996) demonstrated two 8p regions of deletion in a series of bladder carcinomas, one distal to and another proximal to loci inclusive of D8S259, although the marker order D8S505-D8S259-D8S513 was used rather than the D8S259-D8S513-D8S505 order used here. Inspection of their data also suggests the presence of a staggered "breakpoint" overlapping the proximal region of deletion and inclusive of loci D8S535, D8S505, D8S259, and D8S513. Moreover, realignment of these markers to conform with the order used in the current study does not essentially change the interpreation of their results.

A study by Trapman et al. (1994) demonstrated a large region of contiguous distal $8 p$ allelic loss suggestive of a breakpoint proximal to nearby D8S137 (which maps distal to D8S259) in 9 of 26 prostates with $8 \mathrm{p}$ loss. Similarly, Farrington et al. (1996) defined one region of $8 \mathrm{p}$ loss distal to and another proximal to D8S137 in a series of colorectal carcinomas. A previous study from our laboratory also defined two separate regions of deletion distal to D8S137 as well as a third region of deletion proximal to that marker (Macoska et al., 1995). Vocke et al. (1996) described a major region of $8 \mathrm{p}$ deletion distal to and inclusive of D8S137, although it was more limited in extent than the major distal regions of deletion described in the other studies cited above.

Thus, it appears that all of these studies basically agree with a finding of one or more distal regions of $8 \mathrm{p}$ loss extending proximal to D8S137/D8S259, although they disagree on the presence of a separate region of $8 \mathrm{p}$ loss proximal to these markers.
The basis of these discrepancies may be that 1 ) these studies did not examine the allelic loss pattern for markers mapping between D8S137/ D8S259 and D8S87; 2) the physical order of markers mapping between D8S137/D8S259 and D8S87 is ambiguous, making data interpretation difficult; 3 ) the number of tumors examined in some studies may have been insufficient for the detection of discrete regions of allelic loss; and 4) there were probably differences in DNA preparation and gel evaluation, because fractional allelic loss frequencies range from $22 \%$ to $89 \%$ in these studies (MacGrogan et al., 1994; Trapman et al., 1994; Kagan et al., 1995; Macoska et al., 1995; Takle and Knowles, 1996; Farrington et al., 1996; Vocke et al., 1996).

It is interesting that the putative proximal $8 \mathrm{p}$ breakpoint identified here appears to be "staggered," in that it spans at least one megabase. Such "staggered" breakpoints have been observed for other chromosomes, notably the X chromosome, and have been implicated in the formation of dicentric isochromosomes (Wolff et al., 1996). Loss of $8 p$ sequences apparently concurrent with $8 \mathrm{q}$ gain has been observed in prostate tumors by using FISH (Macoska et al., 1994) and comparative genomic hybridization (Visakorpi et al., 1995) techniques, potentially resulting from iso(8q) chromosome formation (Jenkins et al., 1997). The deletion data presented here are consistent with these scenarios.

\section{Identification of a Homozygous Deletion at the D8587 Locus}

One tumor from case 2 (see Fig. 1) failed repeatedly to amplify at the D8S87 locus. To determine whether this was due to homozygous deletion at D8S87, we assayed paired normal and tumor tissue from case 2 by using multiplex PCR with primers to polymorphic sequences at D8S87 and primers to polymorphic sequences mapping distal (D8S505, D8S535) or proximal (D8S255, D8S1121) to D8S87. In all cases, DNA from case 2 tumor tissue failed to amplify at the D8S87 locus. Multiplex reactions showing coamplification of sequences at D8S87 and D8S1121 are shown in Figure 2 and show that two alleles that are 151 and 149 base pairs (bp) in length, respectively, amplify from the D8S87 locus in normal tissues from cases 2 and 23. However, both alleles fail to amplify in tumor tissue from case 2, and only the 149-bp allele amplifies appreciably in tumor tissue from case 23, suggestive of homozygous deletion (case 2) and heterozygous deletion (case 23) of D8S87 sequences, respectively. Coamplification of trinucleo- 
tide repeat sequences at the D8S1121 locus reveals equivalent amplification of alleles $121 \mathrm{bp}$ and 118 bp in size in normal tissue from case 2 and of alleles $124 \mathrm{bp}$ and $115 \mathrm{bp}$ in size in normal tissue from case 23. However, the corresponding tumors demonstrate heterozygous loss involving allele 121 in tumor 2 and heterozygous loss involving allele 124 in tumor 23. Furthermore, PCR analysis of loci producing amplicons larger than that of the D8S87 locus (e.g., the D8S549, D8S513, D8S505, D8S535, and D8S538 loci) was successful (see Fig. 1), suggesting that failure to amplify sequences from the tumor from case 2 DNA at the D8S87 locus was not due to DNA degradation. The ability to amplify sequences from one chromosome 8 homologue at the D8S1121 locus and the concurrent inability to amplify sequences from either chromosome 8 homologue at the D8S87 locus are consistent with the presence of a small homozygous deletion including the D8S87 locus in the tumor from case 2. This is the first report of homozygous deletion in this region of $8 p$ in human tumors. Interestingly, the tumor from case 2 did not demonstrate homozygous loss at the D8S505 locus, which colocalizes to a 1.4 Mb CEPH yeast artifical chromosome, 898-G-11, suggesting that the region of homozygous loss may be less than $1.4 \mathrm{Mb}$ in length.

To further verify the putative homozygous deletion at D8S87 in tumor 2, we performed FISH experiments. A human BAC clone, 303f13, containing sequences amplifiable at the D8S87 locus was labeled via nick translation with fluoresceinlabeled dUTP (Amersham) and cohybridized with a rhodamine-labeled chromosome 8 centeromerespecific probe (Spectrum CEP8; Vysis) to the same normal and tumor tissues from case 2 (with the putative homozygous deletion at D8S87 by PCR analysis) and case 512 (with no deletion at D8S87 by PCR analysis). Two hundred nuclei from each of the four hybridized tissues were then enumerated for the number of D8S87-specific ("8p") and centromere-specific (" $8 \mathrm{c}$ ") probe signals (Table 1). Five types of nuclei were scored: those with $8 \mathrm{p}, 8 \mathrm{c}$ counts equal to 1,1 (presumed monosomic for chromosome 8), 0,2 (presumed homozygous loss of $8 \mathrm{p}$ sequences), 1,2 (presumed heterozygous loss of $8 \mathrm{p}$ sequences), 2,2 (presumed disomic, with retention of $8 \mathrm{p}$ and $8 \mathrm{c}$ sequences), and other. Our data demonstrated a loss of $83 \%$ of D8S87-specific signal in the case 2 tumor compared with $25 \%$ in the corresponding normal tissue section. In contrast, case 512 demonstrated a loss of $38 \%$ of D8S87-specific signal in both normal and tumor tissue sections (Table 1). These data are consistent

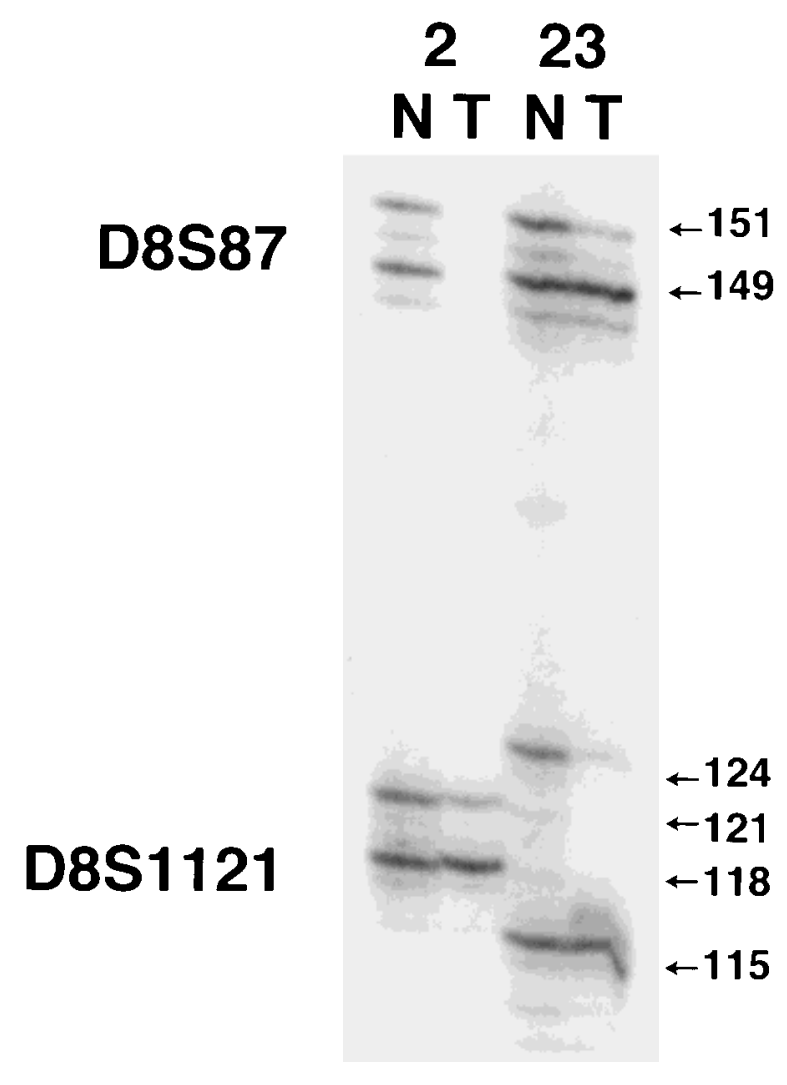

Figure 2. Homozgyous deletion at the D8S87 locus in a prostate tumor. Autroradiograph of a gel showing the results of multiplex polymerase chain reaction analysis using primers to the D8S87 and D 8S1121 loci in paired normal (N) and tumor (T) tissues from cases 2 and 23. Alleles that are 151 and 149 base pairs (bp) in length, respectively, from the D 8587 locus amplify equivalently in normal tissues from cases 2 and 23 . However, both alleles fail to amplify in tumor tissue from case 2, and only the 149-bp allele amplifies appreciably in tumor tissue from case 23 , suggesting a homozygous deletion (case 2 ) and a heterozygous deletion (case 23) of D8S87 sequences, respectively. C oamplification of trinucleotide repeat sequences at the D 851121 locus reveals equivalent amplification of 121-bp and 118-bp alleles in normal tissue from case 2 and of 124-bp and 115-bp alleles in normal tissue from case 23. However, the corresponding tumors demonstrate heterozygous losses involving a 121-bp allele in the tumor from case 2 and a 124-bp allele in the tumor from case 23 . The ability to amplify sequences from one chromosome 8 homologue at the D8S1121 locus and the concurrent inability to amplify sequences from either chromosome 8 homologue at the D 8587 locus are consistent with the presence of a small homozygous deletion, including the D8S87 locus in the tumor from case 2 .

with the PCR data, suggesting complete or nearly complete loss of D8S87-specific sequences in case 2, with retention of the same sequences in case 512 . The degree of apparent loss of D8S87-specific sequences in the normal tissues of case $2(20 \%)$ and in both tissues from case $512(33-36 \%)$ is consistent with that obtained from sectioned tissue and is likely to be due to "slice artifact," as reported previously (Wolman et al., 1993; .Macoska et al., 1994; Jenkins et al., 1997).

Homozygous deletion has been interpreted in other studies as indicating the physical localization 
TABLE 2. Correlation of $8 p$ D eletional D o mains W ith C linical and Pathological Parameters

\begin{tabular}{|c|c|c|c|c|}
\hline \multirow[b]{2}{*}{ Parameter } & \multicolumn{4}{|c|}{ Type } \\
\hline & Distal & $\begin{array}{l}\text { Distal + } \\
\text { proximal }\end{array}$ & Proximal & None \\
\hline \multicolumn{5}{|l|}{ Stage } \\
\hline $\mathrm{LN}+(n=11)$ & 3 & 3 & 1 & 4 \\
\hline$T 4(n=6)$ & 3 & 1 & 1 & 1 \\
\hline T3 $(n=32)$ & 9 & 8 & 6 & 9 \\
\hline T2 $(n=36)$ & 8 & 13 & 8 & 7 \\
\hline \multicolumn{5}{|l|}{ Grade } \\
\hline $5,6(n=20)$ & 6 & 5 & 5 & 4 \\
\hline $7(n=38)$ & 9 & 12 & 8 & 9 \\
\hline $8,9(n=27)$ & 8 & 3 & 3 & 8 \\
\hline \multicolumn{5}{|l|}{ Preoperative PSA ${ }^{a}$} \\
\hline $0.0-4.0(n=12)$ & 1 & 4 & 5 & 2 \\
\hline $4.1-10.0(n=28)$ & 11 & 5 & 3 & 9 \\
\hline $10.1-20.0(n=19)$ & 3 & 7 & 4 & 5 \\
\hline$>20.1(n=26)$ & 8 & 9 & 4 & 5 \\
\hline \multicolumn{5}{|l|}{ Age (years) } \\
\hline $39-54(n=15)$ & 4 & 3 & 2 & 6 \\
\hline $55-65(n=38)$ & 9 & 15 & 7 & 7 \\
\hline $66-75(n=31)$ & 9 & 7 & 7 & 8 \\
\hline ND $(n=1)$ & 1 & & & \\
\hline
\end{tabular}

$\mathrm{LN}^{+}$-metastatic to regional lymph nodes

aPSA, prostate-specific antigen; N D, no date.

of tumor-suppressor genes, and, most recently, it aided in the molecular cloning of two such genes, DPG-4 (Hahn et al., 1996) and PTEN (Li et al., 1997). Therefore, evidence of homozygous loss of the D8S87 locus in a human prostate tumor is consistent with the hypothesis that a proximal 8p tumor-suppressor gene is important in prostate tumorigenesis and maps this tumor-suppressor gene more precisely to a location at or near the D8S87 locus.

\section{Correlation of $8 p$ Deletional Regions with Clinical and Pathological Parameters}

The frequency of distal, distal+ proximal, proximal, and lack of allelic loss was correlated with tumor pathologic stage, combined Gleason score (grade), preoperative serum PSA values, and age at diagnosis of the PCa patients in this study group. A breakdown of the number of tumors in each category is provided in Table 2. There were no statistically significant differences between the number of tumors in each of the four categories (distal, distal + proximal, proximal, and lack of allelic loss) in relation to pathologic stage $(P=0.924)$, grade $(P=0.890)$, preoperative PSA $(P=0.224)$, or age at diagnosis $(P=0.558)$. Because ethnic origin was not recorded for 28 of $85(33 \%)$ patients included in this study, statistical evaluation of that variable was not attempted.

\section{CONCLUSIONS}

In conclusion, this study identifies the physical location of a proximal $8 \mathrm{p}$ breakpoint, and it demonstrates a novel homozygous deletion of the proximal D8S87 locus in human prostate tumors. The data are consistent with the hypothesis that a proximal $8 \mathrm{p}$ tumor-suppressor gene that is important for prostate tumorigenesis maps at or near the D8S87 locus and should facilitate the isolation and cloning of candidate tumor-suppressor genes from this region.

\section{ACKNOWLEDGMENTS}

J.A.M. was supported by grant R29 CA60948 from the National Institutes of Health and by funds from the Section of Urology, Department of Surgery, the University of Michigan.

\section{REFERENCES}

Bergerheim USR, Kunimi K, Collins VP, Ekman P (1993) Deletion mapping of chromosomes 8,10 and 16 in human prostatic carcinoma. Genes Chromosomes Cancer 3:215-220.

Bova GS, Carter BS, Bussemakers JG, Emi M, Fujiwara Y, Kyprianou N, Jacobs SC, Robinson JC, Epstein JI, Walsh PC, Isaacs WB (1993) Homozygous deletion and frequent allelic loss of chromosome 8p22 loci in human prostate cancer. Cancer Res 53:38693873 .

Bova GS, MacGrogan D, Levy A, Pin SS, Bookstein R, Isaacs WB (1996) Physical mapping of chromosome 8p22 markers and their homozygous deletion in a metastatic prostate cancer. Genomics 35:46-54.

Crundwell MC, Chughtai S, Knowles M, Takle L, Lutscombe M, Neoptolemos JP, Morton DG, Phillips SMA (1996) Allelic loss on chromosomes $8 \mathrm{p}, 22 \mathrm{q}$, and $18 \mathrm{q}(D C C)$ in human prostate cancer. Int J Cancer 69:295-300.

Farrington SM, Cunningham C, Boyle SM, Wyllie AH, Dunlop MG (1996) Detailed physical and deletion mapping of 8p with isolation of YAC clones from tumour suppresor loci involved in colorectal cancer. Oncogene 12:1803-1808.

Fujiwara H, Ohata H, Kuroki T, Koyama K, Tsuchiya E, Monden M, Nakamura Y (1995) Isolation of a candidate tumor suppressor gene on chromosome 8p21.3-p22 that is homologous to an extracellular domain of the PDGF receptor beta gene. Oncogene 10:891-895.

Hahn SA, Schutte M, Shamsul Hoque ATM, Moskaluk CA, daCosta LT, Rozenblum E, Weinstein CL, Fischer A, Yeo CJ, Hruban RH, Kern SE (1996) DPC4, a candidate tumor suppressor gene at human chromosome 18q21.1. Science 271:350-353.

Jenkins RB, Qian J, Lieber MM, Bostwick DG (1997) Detection of c-myc oncogene amplification and chromosomal anomalies in metastatic prostatic carcinoma by fluorescence in situ hybridization. Cancer Res 57:524-531.

Kagan J, Stein J, Babaian RJ, Joe YS, Pisters LL, Glassman AB, von Eschenbach AC, Troncoso P (1995) Homozygous deletions at $8 \mathrm{p} 22$ and 8 p21 in prostate cancer implicate these regions as the sites for candidate tumor suppressor genes. Oncogene 11:21212126.

Li J, Yen C, Liaw D, Podsypanina K, Bose S, Wang SI, Puc J, Milaresis C, Rodgers L, McCombie R, Bigner SH, Giovanelli BC, Ittmann M, Tycko B, Hibshoosh H, Wigler MH, Parsons R (1997) $P T E N$, a putative tyrosine phosphatase gene mutated in human brain, breast, and prostate cancer. Science 275:1943-1947.

MacGrogan D, Levy A, Bostwick D, Wagner M, Wells D, Bookstein $\mathrm{R}$ (1994) Loss of chromosome arm 8p loci in prostate cancer: Mapping by quantitative allelic imbalance. Genes Chromosomes Cancer 10:151-159.

Macoska JA, Micale MA, Sakr WA, Benson PD, Wolman SR (1993) Extensive genetic alterations in prostate cancer revealed by dual PCR and FISH analysis. Genes Chromosomes Cancer 8:88-97.

Macoska JA, Trybus TM, Sakr WA, Wolf MC, Benson PD, Powell IJ, Pontes JE (1994) Fluorescence in situ hybridization (FISH) 
analysis of $8 \mathrm{p}$ allelic loss and chromosome 8 instability in human prostate cancer. Cancer Res 54:3824-3830.

Macoska JA, Trybus TM, Benson PD, Sakr WA, Grignon DJ, Wojno KD, Pietruk T, Powell IJ (1995) Evidence for three tumor supressor gene loci on chromosome $8 \mathrm{p}$ in human prostate cancer. Cancer Res 55:5390-5395.

Nihei N, Ichikawa T, Kawana Y, Kuramochi H, Kugoh H, Oshimura M, Hayata I, Shimazaki J, Ito H (1996) Mapping of metastasis suppressor gene(s) for rat prostate cancer on the short arm of human chromosome 8 by irradiated microcell-mediated transfer. Genes Chromosomes Cancer 17:260-268.

Sakr WA, Macoska JA, Benson PD, Grignon DJ, Wolman SR, Pontes JE, Crissman JD (1994) Allelic loss in locally metastatic, multisampled prostate cancer. Cancer Res 54:3273-3277.

Suzuki H, Emi M, Komiya A, Fujiwara Y, Yatani R, Nakamura Y, Shimazaki J (1995) Localization of a tumor suppressor gene associated with progression of human prostate cancer within a 1.2 $\mathrm{Mb}$ region of 8p22-21.3. Genes Chromosomes Cancer 13:168-174.

Takle LA, Knowles MA (1996) Deletion mapping implicates two tumor suppressor genes on chromosome $8 \mathrm{p}$ in the development of bladder cancer. Oncogene 12:1083-1087.

Trapman J, Sleddens HFBM, van der Weiden MM, Dinjens WNM, Konig JJ, Schroder FH, Faber PW, Bosman FT (1994) Loss of heterozygosity of chromosome 8 microsatellite loci implicates a candidate tumor suppressor gene between the loci D8S87 and D8S133 in human prostate cancer. Cancer Res 54:6061-6064.
Trybus TM, Burgess AC, Wojno KJ, Glover TW, Macoska JA (1996) Distinct areas of allelic loss on chromosomal regions $10 \mathrm{p}$ and $10 \mathrm{q}$ in human prostate cancer. Cancer Res 56:2263-2267.

Visakorpi T, Kallioniemi AH, Syvanen AC, Hyytinen ER, Karhu R, Tammela T, Isola JJ, Kallioniemi OP (1995) Genetic changes in primary and recurrent prostate cancer by comparative genomic hybridization. Cancer Res 55:342-347.

Vocke C, Pozzatti RO, Bostwick DG, Florence CD, Jennings SB, Strup SE, Duray PH, Liotta LA, Emmert-Buck MR, Linehan WM (1996) Analysis of 99 microdissected prostate carcinomas reveals a high frequency of allelic loss on chromosome 8p12-21. Cancer Res 56:2411-2416

Wolff DJ, Miller AP, Van Dyke DL, Schwarts S, Willard HF (1996) Molecular definition of breakpoints associated with human $\mathrm{Xq}$ isochromosomes: Implications for mechanisms of formation. Am J Hum Genet 58:154-160.

Wolman SR, Macoska JA, Micale MA, Sakr WA (1992) An approach to definition of genetic alterations in prostate cancer. Diag Mol Pathol 1:192-199.

Ye L, Nakura J, Mitsuda N, Fujioka Y, Kamino K, Ohta T, Jinno Y, Niikawa N, Miki T, Ogihiara T (1995) Genetic association between chromosome 8 microsatellite (MS8-134) and Wener syndrome (WRN): Chromosome microdissection and homozygosity mapping. Genomics 28:566-569. 